\title{
Native Separation and Metallation Analysis of SOD1 Protein from the Human Central Nervous System: a Methodological Workflow
}

Stéphane Roudeau,* Benjamin G. Trist, Asuncion Carmona, Katherine M. Davies, Glenda M. Halliday, Yann Rufin, Stéphane Claverol, Stijn J.M. Van Malderen, Gerald Falkenberg, Kay L. Double, and Richard Ortega*

Cite This: Anal. Chem. 2021, 93, 11108-11115

Read Online

ACCESS | 네 Metrics \& More | 回 Article Recommendations | st Supporting Information

ABSTRACT: Studies of the metal content of metalloproteins in tissues from the human central nervous system (CNS) can be compromised by preparative techniques which alter levels of, or interactions between, metals and the protein of interest within a complex mixture. We developed a methodological workflow combining size exclusion chromatography, native isoelectric focusing, and either proton or synchrotron X-ray fluorescence within electrophoresis gels to analyze the endogenous metal content of copper-zinc superoxide dismutase (SOD1) purified from minimal amounts $(<20 \mathrm{mg})$ of post-mortem human brain and spinal cord tissue. Abnormal metallation and aggregation of SOD1 are suspected to play a role in amyotrophic lateral sclerosis and Parkinson's disease, but data describing SOD1

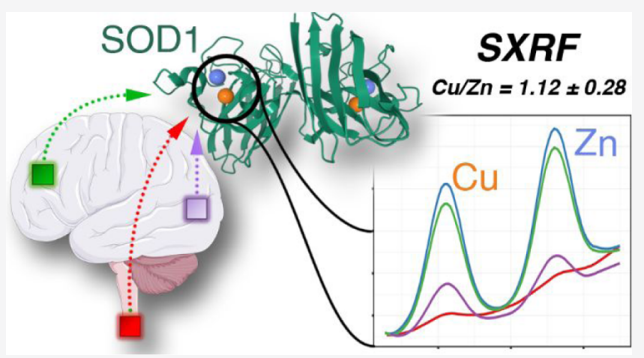
metal occupancy in human tissues have not previously been reported. Validating our novel approach, we demonstrated step-by-step metal preservation, preserved SOD1 activity, and substantial enrichment of SOD1 protein versus confounding metalloproteins. We analyzed tissues from nine healthy individuals and five CNS regions (occipital cortex, substantia nigra, locus coeruleus, dorsal spinal cord, and ventral spinal cord). We found that $\mathrm{Cu}$ and $\mathrm{Zn}$ were bound to SOD 1 in a ratio of $1.12 \pm 0.28$, a ratio very close to the expected value of 1 . Our methodological workflow can be applied to the study of endogenous native SOD1 in a pathological context and adapted to a range of metalloproteins from human tissues and other sources.

$\mathrm{T}$ he physiological structure and function of numerous cellular proteins are dependent upon the binding of one or more metal cofactors; without appropriate metal binding, many essential metabolic pathways are compromised, including mitochondrial respiration, neurotransmitter synthesis, antioxidant defense and axonal trafficking. ${ }^{1}$ A number of neurodegenerative disorders, including Alzheimer's disease $(\mathrm{AD})$, Parkinson's disease (PD), and amyotrophic lateral sclerosis (ALS), exhibit signs of cellular metal dysregulation and metalloprotein dysfunction, which are increasingly thought to contribute to neuronal dysfunction and death in these disorders. $^{2,3}$ While there is a clear need to examine metalloprotein metal binding in these disorders, determining the native metal occupancy of metalloproteins is anything but trivial. Most of the analytical methods used for metal-protein characterization in cells or tissues rely on a protein separation process (e.g., chromatography and gel electrophoresis) coupled to metal analysis techniques such as atomic absorption spectrometry, inductively coupled plasma-mass spectrometry (ICP-MS), or synchrotron X-ray fluorescence (SXRF). Since the early suggestion to combine gel electrophoresis for protein separation and direct metal analysis of the protein bands using particle-induced X-ray emission $(\mathrm{PIXE})^{4}$ or $\mathrm{SXRF}^{5}$ this hyphenated analytical approach has been constantly improved. $^{6-10}$ Other metal detection methods have also been successfully applied to determine the protein metallation directly on electrophoresis gels, for example, using metalselective fluorescent probes ${ }^{11}$ or mass spectrometry techniques. ${ }^{12,13}$ However, this process remains particularly challenging when protein $(s)$ of interest must be isolated and purified from thousands of other proteins in complex cellular or tissue extracts, while maintaining endogenous metal occupancy. These challenges can, in part, be overcome by producing very high levels of the target protein in transgenic expression systems in vitro or in vivo to achieve sufficient sensitivity. ${ }^{14-16}$ Methods employed for these transgenic systems are, however, not appropriate to investigate the native metal occupancy of target metalloproteins in human tissues, primarily owing to the lower relative abundance of target proteins and greater proteomic complexity within these tissues. Here, we present a novel method which couples size exclusion chromatography (SEC) with in-gel isoelectric focusing (IEF), SXRF, and PIXE analyses to quantify the native metallation of copper-zinc

Received: March 15, 2021

Accepted: June 24, 2021

Published: August 4, 2021 


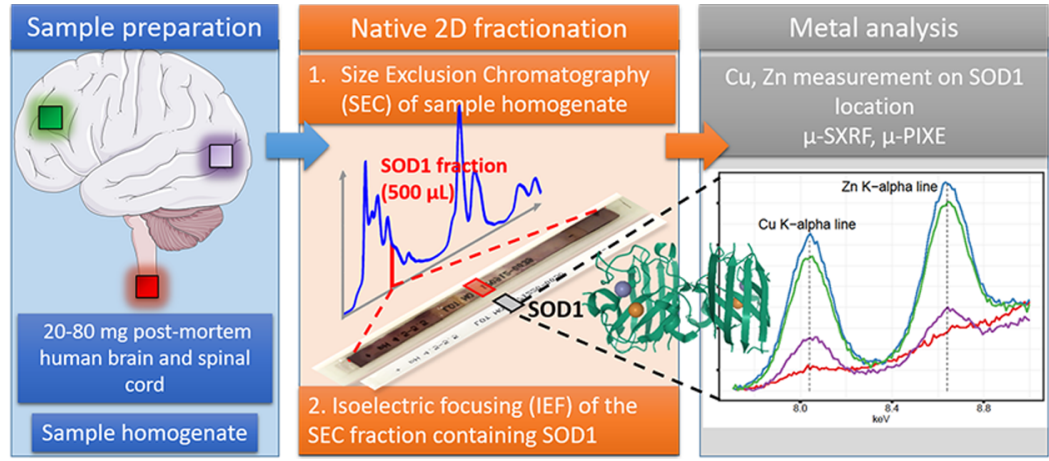

Figure 1. Schematic workflow of the overall analytical process. Human tissue extracts [e.g., from anterior cingulate cortex (green), occipital cortex $(\mathrm{OCx})$ (purple), and spinal cord (red)] were first separated by molecular weight using SEC, and then, SOD1-containing SEC fractions further partitioned across immobilized $\mathrm{pH}$ gradient (IPG) gels, according to isoelectric point ( $\mathrm{pI}$ ) using native IEF, hereon termed native two-dimensional (2D) fractionation. The position of enzymatically active SOD1 within focused IPG gels was then identified using nitroblue tetrazolium (NBT)based activity assay, and metal analyses performed on this position within an unstained duplicate IPG gel using PIXE or by SXRF.

superoxide dismutase (SOD1, $32 \mathrm{kDa}$ homodimer, one copper- and one zinc-binding site per monomer ${ }^{17}$ ) in human post-mortem tissues. We show that our method is capable of quantifying the native metallation of SOD1 protein isolated from minimal amounts of $(\sim 20 \mathrm{mg})$ post-mortem human brain and spinal cord tissue.

The SOD1 metalloprotein is widely studied because it plays a vital role in protecting against oxidative stress ${ }^{18}$ and is also implicated in the aetiology of several devastating neurodegenerative diseases. ${ }^{19,20}$ Mutations in the SOD1 gene were identified for familial forms of $\mathrm{ALS}^{21}$ and produce abnormal forms of misfolded, mutant SOD1 protein, resulting in the death of motor neurons. ${ }^{22}$ Moreover, mounting data suggest that misfolded, wild-type SOD1 may also contribute to neuron death in the more prevalent sporadic form of ALS, ${ }^{23}$ as well as in $\mathrm{AD}^{24}$ and PD. ${ }^{25}$ While it is unclear how misfolded mutant and wild-type SOD1 result in neuron death in these disorders, there is growing consensus that SOD1 misfolding may result from alterations to SOD1 metal binding. ${ }^{26,27}$ Nevertheless, there is currently no data describing native, endogenous SOD1 metal occupancy in human tissues. Our method enables the measurement of the metallation of endogenous, native SOD1. We applied this workflow to the analysis of post-mortem human tissue consisting of tissues $(20-80 \mathrm{mg}$ ) from five regions of the brain and spinal cord.

\section{EXPERIMENTAL SECTION}

The schematic workflow of the overall analytical process is shown in Figure 1, and the corresponding detailed protocols are presented in Supporting Information (S1).

Samples and Sample Preparation. Fresh frozen postmortem human brain and spinal cord tissues (18-319 mg) from 17 individuals without any diagnosed neurological disorders or neuropathological abnormalities were obtained from the Sydney Brain Bank (Sydney, Australia) and King's College Brain Bank (London, UK) (Table S2 and S3). Soluble protein extracts were prepared under non-denaturating conditions (Supporting Information, S1), fractionated or not using SEC, and then used to perform IEF and metal analysis.

Size Exclusion Chromatography. Chromatographic conditions were optimized to maintain the endogenous biochemical properties of SOD1 protein and are similar to those used by Larner et al. ${ }^{28}$ Soluble protein extracts and SOD1 from human erythrocytes (cSOD1) (Sigma Aldrich,
S9636) solutions were fractionated using a Superdex 75 Increase 10/300 GL column connected to an Äkta Purifier 10 liquid chromatography system, cooled to $4{ }^{\circ} \mathrm{C}$, and using 100 $\mathrm{mM}$ ammonium acetate solution $(\mathrm{pH} 7.4)$ as the eluant. The elution peak of the cSOD1 positive control was observed primarily within fraction 11 (f11), which centered at $11.81 \pm$ $0.10 \mathrm{~mL}$ (mean $\pm \mathrm{SD}, n=6$ over four cycles of column use), with an overlap observed into fraction 12 (Supporting Information, Figure S8). Only fraction 11 of soluble protein extracts, with the highest SOD1 concentration, was used for further analyses. The total protein concentration in $\mathrm{f} 11$ was typically around $20 \mu \mathrm{g} / \mathrm{mL}$. The presence of enzymatically active, dimeric SOD1 in f11 of human tissue extracts was systematically confirmed by NBT activity staining after IEF. ${ }^{16,25}$ Proteomic mass spectrometry analyses of resultant IPG strips also confirmed the SOD1 presence in the f11 fraction.

Native Isoelectric Focusing (Native IEF). All IEF experiments were performed without any chaotropic, reducing, or denaturating agents. Focusing conditions and materials are detailed in Supporting Information (S1). The location of SOD1 on the IPG strip was detected after focusing using NBT activity staining, as previously described. ${ }^{14}$ NBT staining likely introduces trace element contamination, and therefore, strips were run in duplicate to enable determination of SOD1 location in the first strip using NBT and measurement of $\mathrm{Cu}$ and $\mathrm{Zn}$ within the second unstained strip at the corresponding location of SOD1. ${ }^{16}$

SXRF Analysis. The SXRF analyses were performed in the microprobe hutch of the Hard X-ray Micro/Nano-Probe beamline P06 at the synchrotron storage ring PETRA III (DESY) in Hamburg (Germany). ${ }^{29}$ The analyses were carried out with an X-ray beam of $12 \mathrm{keV}$ photon energy, which was selected by a cryogenically cooled Si111 double-crystal monochromator from the spectrum of an undulator source. Triplicates were recorded for each sample, mean $\mathrm{Cu} / \mathrm{Zn}$ ratios were calculated, and standard deviation (SD) of individual samples ranged from 0.01 to 0.04 .

PIXE Analysis. The PIXE analyses were performed at the AIFIRA facility of the CENBG in Gradignan (France) using a 3.5 MV singletron in-line particle accelerator (High Voltage Engineering Europe).

Proteomic Mass Spectrometry. Sample preparation, protein digestion, nanoscale liquid chromatography coupled 
Table 1. Proteomic Mass Spectrometry Analysis of the SOD1 IPG Gel Band ${ }^{a}$

\begin{tabular}{|c|c|c|c|c|c|c|c|c|}
\hline \multirow{2}{*}{$\frac{\text { sample }}{\text { human cerebral cortex }}$} & \multicolumn{2}{|c|}{$\begin{array}{l}\text { total protein concentration } \\
\qquad \mu \mathrm{g} / \mathrm{mL}\end{array}$} & \multicolumn{3}{|c|}{ SOD1 abundance } & \multicolumn{3}{|c|}{ number of proteins detected } \\
\hline & IEF & SEC + IEF (f11) & IEF & SEC + IEF (f11) & enrichment factor & IEF & SEC + IEF (f11) & ratio \\
\hline & 974 & 23 & $0.65 \% *$ & $64.54 \% *$ & 99.1 & 1235 & 350 & 0.28 \\
\hline cSOD1 1 & $10 \mu$ & SEC & n.a. & $97.63 \% *$ & n.a. & n.a. & 20 & n.a. \\
\hline
\end{tabular}

${ }^{a}$ The separation of SOD1 using SEC (fraction f11) before IEF sharply increases the relative abundance of SOD1 with an enrichment factor of 99.1 and a large decrease in the number of proteins detected $(*=$ rounded to the nearest $0.01 \%)$. See Tables S4-S6 for details.

to tandem mass spectrometry (nLC-MS/MS) analysis, and data analysis are detailed in Supporting Information (S1).

\section{RESULTS AND DISCUSSION}

The purpose of this study was to develop a highly sensitive method for characterizing the endogenous metallation state of SOD1 as a metalloprotein that is present in low to moderate levels within a complex protein mixture. SOD1 is one of the 16,227 expressed proteins in the human central nervous system (CNS) (The Human Protein Atlas; https://www.proteinatlas. org/humanproteome/brain/human+brain). To overcome challenges posed by the relatively low abundance of SOD1 and the preservation of its endogenous metallation, we purified SOD1 protein from the human brain and spinal cord tissue extracts using SEC and native IEF (Figure 1). We chose to isolate proteins from CNS tissues under native conditions, according to molecular weight (MW) using SEC and protein pI using native IEF. Following SEC, the protein fraction containing SOD1 was separated by native IEF, and then, its position within IPG gels was identified using in-gel NBT activity assay. Metal analyses were performed on this position within an unstained duplicate gel, run in parallel to avoid trace element contamination originating from the NBT reagents. Metal quantification was conducted using PIXE or SXRF, two quantitative X-ray spectrometry techniques. Both methods can be applied for metalloprotein analysis in electrophoresis gels 7,8 (Figure 1). SXRF has a better detection limit than PIXE (0.1 $\mu \mathrm{g} / \mathrm{g}$ vs $1 \mu \mathrm{g} / \mathrm{g}$ ) and is among the trace metal analysis techniques of solid samples with highest sensitivity. ${ }^{30,31}$ Finally, proteomic analyses of IPG gels at the location of SOD 1 protein were performed using tandem mass spectrometry (MS/MS) to characterize and measure the level of possible confounding metalloproteins.

SOD1 Protein is Enriched as the Most Abundant Protein Following SEC and Native IEF. Proteomic mass spectrometry analyses of excised, SOD1-containing IPG gel strips demonstrated that one-dimensional (1D) fractionation of cortical tissue extracts using native IEF alone drastically increases the relative abundance of SOD1. Within the primary SOD1-containing native IEF fraction, SOD1 constituted $0.65 \%$ of all proteins (Table 1) and represented the 27th most abundant of 1235 proteins at its pI (Table S4). Native 2D fractionation (SEC-IEF) of cortical tissue extracts increased SOD1 enrichment by 99-fold compared with extracts fractionated using native IEF alone, such that SOD1 was identified as the most abundant protein (Table S5) and constituted $65.54 \%$ of all protein present within processed extracts (Table 1). This reflected a further $72 \%$ reduction in extract proteome complexity (350 proteins or protein fragments remaining) following native $2 \mathrm{D}$ fractionation compared with extracts fractionated using native IEF alone. Overall, our SEC-IEF protocol reduced extract proteome complexity by $97.8 \%$ compared with unprocessed cortical tissue extracts, yielding a high enrichment of SOD1 protein suitable for metallation analyses.

Preservation of the SOD1 Protein Conformation and Metallation. We verified that the conformation of the SOD1 protein was preserved during SEC by measuring its $\mathrm{pI}$, which accounts for the overall conformation of the protein. ${ }^{32}$ Data obtained with commercially available positive control solutions of human SOD1 (cSOD1), or with soluble protein extracts derived from human $\mathrm{OCx}$, showed that the $\mathrm{pI}$ was unchanged, demonstrating that SOD1 protein conformation and activity were preserved during SEC (Supporting Information, S7 and Figure S8). Similarly, we measured the $\mathrm{Cu} / \mathrm{Zn}$ ratio of cSOD1 at different steps of sample preparation to check that the protocol did not alter the metallation of SOD1. These measurements confirmed that the $\mathrm{Cu} / \mathrm{Zn}$ ratio of $\mathrm{cSOD} 1$ was preserved during SEC, IEF, or the combination of both chromatographic methods (Supporting Information, Figures and Tables S9-S12).

SOD1-Enriched Protein Extracts Contain Minimal Confounding Metalloproteins. In addition to verifying the preservation of SOD1 pI and metallation state, it was important to assess whether any proteins remaining after native IEF or SEC-IEF fractionation bind $\mathrm{Cu}$ or $\mathrm{Zn}$ and could thus interfere with subsequent measurements of SOD1 metallation. We addressed this question by proteomic mass spectrometry (MS) analyses performed on the SOD1 activity band from IEF gels. Proteomic mass spectrometry results show that SEC enriched SOD1 by a factor of 99.1, with its relative abundance in the activity band increasing from $0.65 \%$ without SEC to 64.54\% with SEC (Table 1). In the SOD1 activity band without SEC before native IEF, SOD1 is in 27 th position in relative abundance $(0.7 \%)$, and other $\mathrm{Cu}$ - or $\mathrm{Zn}$-binding proteins are detected with higher abundance (i.e., serum albumin, $4.1 \%$ relative abundance, and $636 \%$ abundance relatively to SOD1) and could significantly contribute to metal analysis (Table S4). In the SOD1 activity band when SEC is performed before native IEF, SOD1 becomes the most abundant protein $(64.5 \%)$, whereas serum albumin is lowered to $2.4 \%$ relative abundance and $3.7 \%$ abundance relatively to SOD1 (Table S5). Extracellular CuZnSOD (SOD3) was not detected by proteomic MS analyses (Tables S4 and S5). The low relative abundance of albumin suggests that any potential contamination of total $\mathrm{Cu}$ and $\mathrm{Zn}$ levels by albumin-derived metals will be minor. Moreover, as the MW of albumin is higher than that of SOD1 (66.5 vs $32 \mathrm{kDa})$, the majority of albumin is excluded by SEC. Any residual albumin degradation fragments present in the SEC fraction are likely to have lost, at least in part, their metal-binding properties. The sum of the abundances of proteins identified as potentially binding $\mathrm{Cu}$ or $\mathrm{Zn}$ relative to SOD1 is, respectively, 4.6 and $5.9 \%$ (Table S5).

The identification of serum albumin, as well as $\alpha$ - and $\beta$ chains of hemoglobin $(\mathrm{Hb})$, in SOD1-enriched tissue extracts (Table S5) may reflect the presence of blood in the cortical 

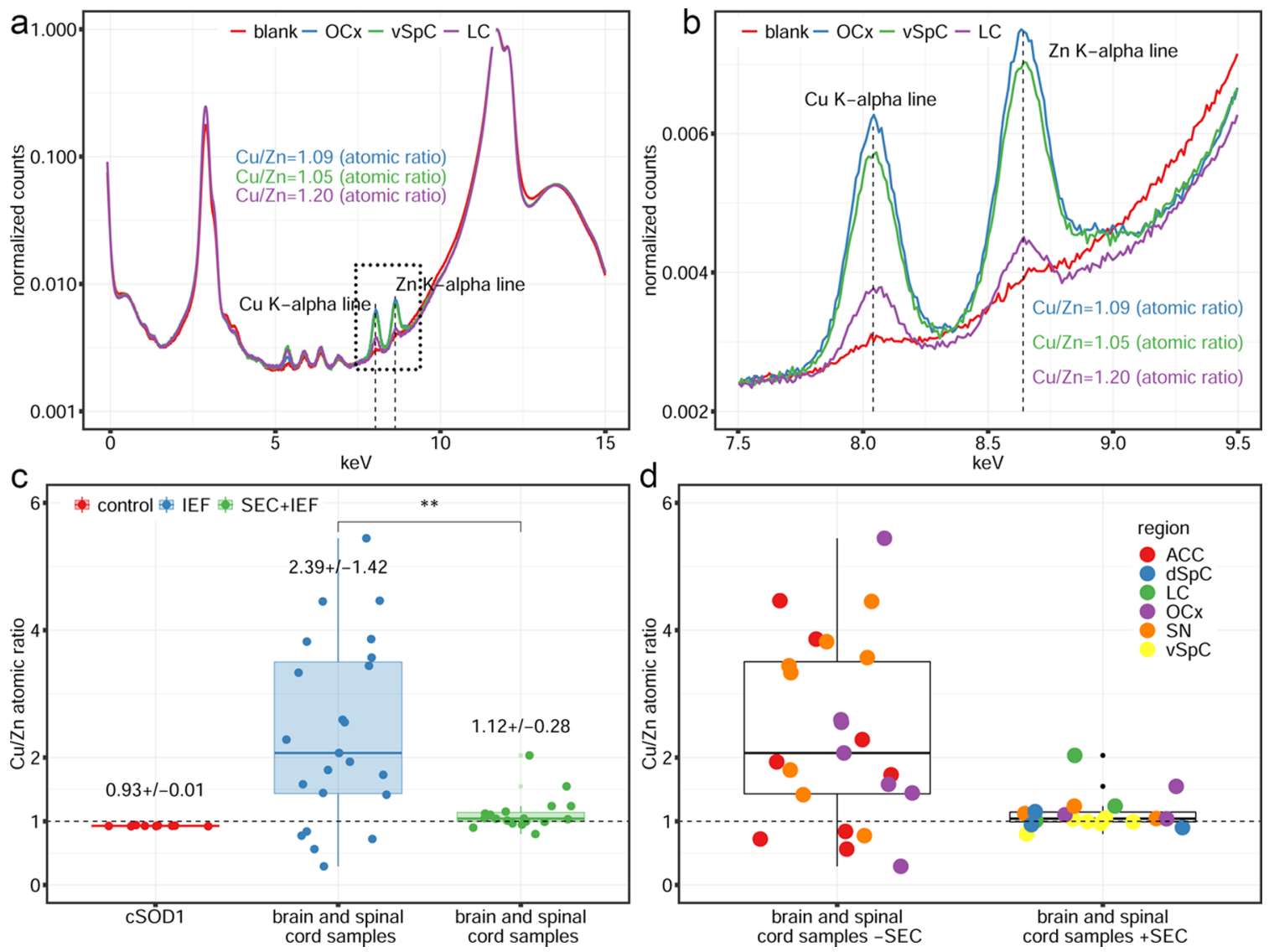

Figure 2. $\mathrm{Cu} / \mathrm{Zn}$ ratios of active SOD1 dimers isolated from the human brain and spinal cord tissues. (a) Representative SXRF spectra obtained for active SOD1 dimers purified from human OCx (blue line), $\mathrm{vSpC}$ (green line), and LC (purple line) after native 2D fractionation (SEC + IEF), and for a control IPG strip (blank, red line). (b) Inset of panel (a) showing more closely the $\mathrm{Cu}$ and $\mathrm{Zn}$ emission energy regions. (c) $\mathrm{Cu} / \mathrm{Zn}$ ratios of active SOD1 dimers isolated from human brain and spinal cord tissues using native IEF alone (IEF; mean $247 \mathrm{mg}$ of frozen hydrated tissue, $n=23$; blue) and native 2D fractionation (SEC + IEF; mean $46 \mathrm{mg}$ of frozen hydrated tissue, $n=18$; green), compared with cSOD1 positive control ( $n=$ 9, red) (see also Table S14). Cu/Zn ratios (mean \pm SD) are significantly elevated in the IEF group compared with the SEC + IEF $(* * p<0.01$, Wilcoxon-Mann-Whitney test, Table S13). (d) Data from (c) are color-coded, according to tissue origin: ACC (red), dSpC (blue), LC (green), OCx (purple), SN (orange), and $\mathrm{vSpC}$ (yellow).

tissue samples. As removal of blood at human brain tissue collection is not routine, the inclusion of some blood contamination from tissues sourced from a human Brain Bank must be expected. Nevertheless, our data suggest that the contribution of erythrocyte-derived SOD1 in our samples is negligible, given the substantially lower abundance of these components ( $\alpha$-chain, $7.44 \%$; $\beta$-chain, $4.56 \%$ ) compared with SOD1 $(64.54 \%)$ in tissue extracts following $2 \mathrm{D}$ fractionation and the naturally low abundance of erythrocytic SOD1 $(<0.2 \%)$ compared with $\mathrm{Hb}$ chains. Removal of obvious blood vessels, and rinsing tissue samples prior to homogenization, may reduce this possible source of $\mathrm{Cu}$ and $\mathrm{Zn}$ contamination. Assessment of the color of human tissue extracts constitutes a basic yet informative quality control step in this regard, with red-colored tissues being associated with higher risk of blood contamination.

Determination of the $\mathrm{Cu} / \mathrm{Zn}$ Ratio in SOD1 from Human Brain and Spinal Cord Tissues. Following method validation, we employed our SEC-IEF-SXRF/PIXE protocol to quantify the amount of $\mathrm{Cu}$ and $\mathrm{Zn}$ bound to enzymatically active SOD1 extracted from fresh frozen human brain and spinal cord tissues. Soluble protein extracts were prepared from approximately $50 \mathrm{mg}$ (mean $46 \mathrm{mg}$ ) of fresh frozen tissue from five brain and spinal cord regions locus coeruleus (LC), substantia nigra ( $\mathrm{SN}), \mathrm{OCx}$, ventral spinal cord ( $\mathrm{vSpC})$, and dorsal spinal cord $(\mathrm{dSpC})$ of nine healthy-aged individuals (cases 9-17, Supporting Information, Table S2 and S3), as previously described (see the experimental section, Supporting Information, S1, and refs 25 and 33). The corresponding soluble protein extracts were then processed by SEC, and the entire SOD1-containing fraction $\mathrm{f} 11$ (about $10 \mu \mathrm{g}$ of total protein) was loaded for IEF prior to metal analysis of the SOD1 activity band (Figure 1). Representative X-ray fluorescence spectra of SEC-IEF-processed human tissue extracts and control IPG strip, as shown in Figure 2a,b, clearly exhibit the K-alpha X-ray emission lines of $\mathrm{Cu}$ and $\mathrm{Zn}$ in SECIEF-processed extracts; in contrast, these X-ray emission lines are below the limit of quantification in the control blank IPG strip. It should be noted that the background-corrected integrated area under the $\mathrm{Zn}$ peak is expected to be larger than the area under the $\mathrm{Cu}$ peak for an atomic ratio of 1 . The $\mathrm{K} \alpha$ energy of $\mathrm{Zn}$ is closer to the primary energy relative to the $\mathrm{K} \alpha$ energy of $\mathrm{Cu}$, resulting in a higher areal sensitivity for $\mathrm{Zn}$ (as expressed by cts $/ \mathrm{g} / \mathrm{cm}^{2} / \mathrm{s}$ ). For the three examples of tissue analyses (OCx, vSpC, and LC), as illustrated in Figure 2a,b, the $\mathrm{Cu} / \mathrm{Zn}$ ratio of SOD1 was always close to the theoretical expected value of $1(1.09,1.05$, and 1.20 , respectively). Overall, the analyses of SXRF and PIXE spectra reveal that $\mathrm{Cu}$ and $\mathrm{Zn}$ 
were bound to enzymatically active SOD1 dimers derived from all brain and spinal cord samples in a $\mathrm{Cu} / \mathrm{Zn}$ ratio of $1.12 \pm$ 0.28 (Figure $2 \mathrm{c}$ ). These results demonstrate the capacity of our SEC-IEF-SXRF/PIXE protocol for accurately measuring the $\mathrm{Cu} / \mathrm{Zn}$ ratio of SOD1 protein isolated from as little as $20 \mathrm{mg}$ of fresh frozen human brain or spinal cord tissue in its native state.

Comparison of these results with those obtained following 1D (native IEF) fractionation alone reinforces the importance of SEC in reducing metal contamination from other $\mathrm{Cu}$ - or $\mathrm{Zn}$ binding proteins existing at the pI of enzymatically active SOD1 (Figure 2c,d). For experiments utilizing native IEF alone, soluble protein extracts were prepared from approximately $250 \mathrm{mg}$ (mean $247 \mathrm{mg}$ ) of fresh frozen tissue from three brain regions $\mathrm{SN}, \mathrm{OCx}$, and anterior cingulate cortex (ACC), of eight healthy-aged individuals (cases 1-8, Supporting Information, Tables S2 and S3). An average $\mathrm{Cu}$ / $\mathrm{Zn}$ ratio of $2.39 \pm 1.42$ was observed in brain tissue extracts (SN, ACC, and $\mathrm{OCx}$ ) processed using native IEF without prior SEC, which significantly differs from the $\mathrm{Cu} / \mathrm{Zn}$ ratio measured for enzymatically active SOD1 isolated from human tissues using 2D fractionation (Wilcoxon-MannWhitney test; $p=0.003$, Supporting Information, Table $S 13$ ), and differs from the $0.93 \pm 0.01$ value measured for cSOD1 used as a positive control to check the quality and reproducibility of the metal analyses (Figure 2c). SEC thus clearly improves both the accuracy of $\mathrm{Cu}$ and $\mathrm{Zn}$ measurements and also the precision of these measurements, as evidenced by a 5 -fold improvement in the $\mathrm{SD}$ of $\mathrm{Cu} / \mathrm{Zn}$ ratio measurements ( 0.28 with SEC vs 1.48 without SEC). We also observed that regional variability in the $\mathrm{Cu} / \mathrm{Zn}$ ratio is small (Figure 2d, +SEC), showing no statistically significant difference between regions (Table S13). Similarly, the higher $\mathrm{Cu} / \mathrm{Zn}$ ratios and increased dispersion observed without SEC are not related to the tissue type (Figure 2d, SEC; Table S13). Furthermore, we did not observe any significant difference between individuals whose tissues were treated using the same procedure (Figure S15 and Table S13).

The method presented here allows the successful isolation of a metalloprotein from a complex protein mixture and quantification of its native metal binding. The presence of one $\mathrm{Cu}$ - and one $\mathrm{Zn}$-binding site per SOD1 monomer is well accepted, but very few studies have reported a $\mathrm{Cu} / \mathrm{Zn}$ ratio close to 1 in biological samples. We have previously shown in enzymatically active SOD1 that the metallation ratio varies by about $20 \%$ (from 0.85 to 1.19 ), depending on the pI of the wild-type isoforms concerned. ${ }^{16} \mathrm{We}$ previously observed a correlation between reductions in the $\mathrm{Cu} / \mathrm{Zn}$ ratio and net charge of these different SOD1 isoforms, indicating that slight variations in the metallation of enzymatically active SOD1 isoforms are associated with differences in protein solubility, which may affect the propensity for SOD1 to precipitate and aggregate. Quantification of endogenous SOD1 metallation has previously only been reported in yeast cellular models overexpressing human wild-type SOD1, with $\mathrm{Cu} / \mathrm{Zn}$ ratios ranging from 0.85 to 1.19 , as measured by native-IEF and PIXE analyses. ${ }^{14,16}$ This approach cannot be used to study human samples, however, because of the lower SOD1 expression and higher protein complexity in human samples. Very few studies report metallation of SOD1 in human brain or spinal cord tissues. Recently, SOD1 Cu content, but not $\mathrm{Zn}$ content, has been quantified by ICP-MS for SOD1 protein separated by SEC from post-mortem human frontal cortex. ${ }^{28}$
Larner and colleagues used SEC conditions for native SOD1 separation similar to those performed in this study, resulting in impressive results describing $\mathrm{Cu}$ isotopic characterization. Their study did not, however, aim to determine $\mathrm{Cu} / \mathrm{Zn}$ ratios since SEC alone would not enable full separation of SOD1 from other Zn-binding confounding metalloproteins. To our knowledge, our study is the first to report a $\mathrm{Cu} / \mathrm{Zn}$ ratio $(1.12$ \pm 0.28 ) close to the theoretical value of 1 within enzymatically active SOD1 isolated from human tissues. This result highlights the importance of characterizing by proteomic analysis tissue extracts for metalloproteins other than the target protein prior to metal analyses, particularly when analyzing samples with lower basal levels of a target protein, such as SOD1, in native CNS tissues. A limitation of our study is that it remains difficult to measure the exact stoichiometry of $\mathrm{Cu}$ and $\mathrm{Zn}$ per monomer of SOD1, which would require the measurement of the exact amount of SOD1 protein analyzed by SXRF/PIXE in IPG gels. We attempted to solve this challenge by using the X-ray fluorescence signal of the sulfur atoms within SOD1's four cysteine residues (residues 6, 57, 111, and 146); however, the sulfur content within our experimental buffer solutions rendered the cysteine residue sulfur signal indistinguishable from background noise.

The hypothesis that changes in SOD1 metallation underlie pathogenic aggregation of SOD1 in neurodegenerative disease $2,3,24-27,34,35$ stimulated development of therapeutic strategies using metal-based compounds which aim to correctly metallate SOD1. This approach results in the promising data in animal models of ALS, ${ }^{15,36,37}$ but the relationship between SOD1 mismetallation and SOD1 aggregation in human disease remains unknown. Characterization of SOD1 metallation in humans is challenging due to relatively low expression of SOD1 in human tissues, as well as increased proteomic complexity, including potentially confounding $\mathrm{Cu}-$ and $\mathrm{Zn}$ binding proteins. To overcome these difficulties, most studies investigating metal dysregulation in SOD1 aggregation till date have utilized transgenic cellular or animal systems exhibiting up to 17 -fold overexpression of SOD1 protein. ${ }^{38}$ Studies conducted in systems overexpressing SOD1 protein generally report a $\mathrm{Cu}$ deficiency in human wild-type SOD1. ${ }^{20}$ For example, human wild-type SOD1 isolated from SOD1overexpressing insect cells using hydrophobic interaction chromatography exhibits a $\mathrm{Cu} / \mathrm{Zn}$ ratio ranging from $0.11-$ 0.33 , as measured by ICP-MS, with variability depending on the degree of $\mathrm{Cu}$ supplementation in culture medium. ${ }^{39-41}$ Human wild-type SOD1 protein purified from SOD1-overexpressing yeast using ICP-MS analysis is reported to express a $\mathrm{Cu} / \mathrm{Zn}$ ratio of $0.21 ;^{42}$ similarly, wild-type SOD 1 from the spinal cord and brain of transgenic SOD1 mice is reported to express $\mathrm{Cu} / \mathrm{Zn}$ ratios of approximately 0.4 for both tissues, as measured using high-performance liquid chromatography coupled with ICP-MS. ${ }^{43} \mathrm{Cu} / \mathrm{Zn}$ ratios lower than 1 are also reported for mutant SOD1 proteins over-expressed in animal models. ${ }^{15,36,37}$

Although these studies are helpful to compare the relative metallation of wild-type versus mutant SOD1, or to study the efficiency of pharmacological approaches to re-metallate SOD1, it is concerning that wild-type SOD1 protein purified from many common transgenic cellular and animal expression systems does not exhibit full metal occupancy. ${ }^{20}$ It is unknown whether the observed reduced $\mathrm{Cu} / \mathrm{Zn}$ ratios of mutant and wild-type SOD1 proteins isolated from transgenic cell lines and animal models derive from altered SOD1 protein metal 
binding, from altered proportions of metal-free, metaldeficient, and fully metallated SOD1 isoforms in these systems, or alternatively from an incompatibility of human SOD1 overexpression with transgenic models. It would also be of interest to quantify the metallation and abundance of monomeric and dimeric SOD1 isoforms lacking enzymatic activity as these protein forms are reported to play key roles in SOD1 aggregation and neurotoxicity. ${ }^{26,27}$ For these type of analyses, Rhoads et al. developed a method based on the use of $\mathrm{C} 4$ reversed phase column (Ziptip) and electrospray ionization mass spectrometry for the quantification of apo, holo, and metal-deficient forms in the spinal cord of rats overexpressing SOD $1 .{ }^{44}$ They also improved the mass analysis using a Fourier transform ion cyclotron resonance mass spectrometer to distinguish the relative proportion of the $\mathrm{Zn}$-deficient and $\mathrm{Cu}$-deficient forms at the SOD1 monomer level. ${ }^{45}$

Compared to previously published protocols, using nondenaturating protocols and combining two protein separation techniques, our method preserves the native metallation and avoids the contribution of confounding metalloproteins. It should be emphasized that this hyphenated SEC-IEF-SXRF approach allows, from a small amount of human tissue, to measure the metallation of native endogenous SOD1, without an overexpression system that could alter the physiological metallation. The development and refinement of analytical techniques capable of resolving and quantifying individual SOD1 isoforms, as well as their metal-binding capacities, will be key in evaluating the underlying cause(s) of wild-type and mutant SOD1 mismetallation in these model systems and also in human tissues. The findings from such analyses would represent strong evidence to consider the hypothesis that SOD1 mismetallation is casually associated with cellular dysfunction and death in disease models.

\section{CONCLUSIONS}

The method we present in this study is the first to enable the measurement of metals bound to SOD1, isolated in its native state from a small amount $(\sim 20 \mathrm{mg})$ of the human postmortem brain or spinal cord tissue. Our workflow is suitable for investigating the metallation of a wide range of metalloproteins in complex biological samples, including those where the protein of interest is of moderate or low abundance. We show that purification of SOD1 from human tissue protein extracts using SEC and native IEF does not alter its conformation or metal binding, and enriches it over 100-fold within tissue extracts, clearly distinguishing it from the $\sim 16,000$ other proteins expressed in human nervous tissues. Our experimental workflow minimizes the introduction of metal contaminants or disruption of endogenous protein metal binding which, when combined with our use of high-sensitivity accelerator-based metal analyses, provides unparalleled accuracy and precision of protein metal measurements. Using this method, we show in brain and spinal cord samples from healthy-aged individuals that $\mathrm{Cu}$ and $\mathrm{Zn}$ are bound to enzymatically active SOD1 in a ratio close to the theoretical value of 1 . Our novel workflow is suitable to explore whether alterations to SOD1 metallation are associated with SOD1 deposition and neuronal death in CNS tissues from familial SOD1-ALS, sporadic ALS, or other disorders exhibiting SOD1 dysfunction and accumulation like PD. ${ }^{25}$ This method could also be applied to other native endogenous metalloproteins when only a small amount of tissue is available and excellent sensitivity and reproducibility are required, without the need for an overexpression system.

\section{ASSOCIATED CONTENT}

\section{Supporting Information}

The Supporting Information is available free of charge at https://pubs.acs.org/doi/10.1021/acs.analchem.1c01128.

Detailed experimental protocols and methods; demographic information for post-mortem human tissue cases; information for post-mortem human tissues; proteomic mass spectrometry analysis of SOD1 gel band after native IEF only; proteomic mass spectrometry analysis of SOD1 gel band after SEC and native IEF; proteomic mass spectrometry analysis of cSOD1 gel band after SEC and native IEF; SOD1 protein conformation is preserved during SEC; effect of SEC on $\mathrm{pI}$ and enzymatic activity of SOD $1 ; \mathrm{Cu} / \mathrm{Zn}$ ratios of cSOD1 protein is unchanged following SEC and native IEF; $\mathrm{Cu} / \mathrm{Zn}$ ratios in cSOD 1 separated by SEC and IEF; boxplots median quartile and interquartile range for the $\mathrm{Cu} / \mathrm{Zn}$ atomic ratio of cSOD1 measured by PIXE and SXRF; mean $\mathrm{Cu} / \mathrm{Zn}$ ratio of commercial cSOD1 at different stages of our purification protocol; statistical analysis of data; mean $\mathrm{Cu} / \mathrm{Zn}$ ratio of commercial cSOD1 (control) and active SOD1 dimers isolated from human OCx (brain samples); and boxplots median quartile and interquartile range for the $\mathrm{Cu} / \mathrm{Zn}$ atomic ratio of SOD1 from individual cases (PDF)

\section{AUTHOR INFORMATION}

\section{Corresponding Authors}

Stéphane Roudeau - Univ. Bordeaux, CNRS, CENBG, UMR-5797, F-33170 Gradignan, France; ○ orcid.org/ 0000-0002-4539-9380; Email: roudeau@cenbg.in2p3.fr

Richard Ortega - Univ. Bordeaux, CNRS, CENBG, UMR5797, F-33170 Gradignan, France; 이이.org/00000003-1692-5406; Email: ortega@cenbg.in2p3.fr

\section{Authors}

Benjamin G. Trist - Brain and Mind Centre and School of Medical Sciences (Neuroscience), Faculty of Medicine and Health, The University of Sydney, Sydney, New South Wales 2050, Australia; 10 orcid.org/0000-0002-0712-399X

Asuncion Carmona - Univ. Bordeaux, CNRS, CENBG, UMR-5797, F-33170 Gradignan, France; Brain and Mind Centre and School of Medical Sciences (Neuroscience), Faculty of Medicine and Health and Brain and Mind Centre and Faculty of Medicine and Health, School of Medical Sciences, The University of Sydney, Sydney, New South Wales 2050, Australia; Plateforme Biochimie et Biophysique (BioProt) and Plateforme Proteome, Univ. Bordeaux, F33077 Bordeaux, France; DESY Synchrotron, Hamburg D22603, Germany

Katherine M. Davies - Brain and Mind Centre and School of Medical Sciences (Neuroscience), Faculty of Medicine and Health, The University of Sydney, Sydney, New South Wales 2050, Australia

Glenda M. Halliday - Brain and Mind Centre and Faculty of Medicine and Health, School of Medical Sciences, The University of Sydney, Sydney, New South Wales 2050, Australia; 1 orcid.org/0000-0003-0422-8398 
Yann Rufin - Plateforme Biochimie et Biophysique (BioProt), Univ. Bordeaux, F-33077 Bordeaux, France

Stéphane Claverol - Plateforme Proteome, Univ. Bordeaux, F33076 Bordeaux, France

Stijn J.M. Van Malderen - DESY Synchrotron, Hamburg D22603, Germany; Present Address: Department of Chemistry, Ghent University, Campus De Sterre, Belgium; () orcid.org/0000-0002-3879-7882

Gerald Falkenberg - DESY Synchrotron, Hamburg D-22603, Germany

Kay L. Double - Brain and Mind Centre and School of Medical Sciences (Neuroscience), Faculty of Medicine and Health, The University of Sydney, Sydney, New South Wales 2050, Australia

Complete contact information is available at:

https://pubs.acs.org/10.1021/acs.analchem.1c01128

\section{Notes}

The authors declare no competing financial interest.

\section{ACKNOWLEDGMENTS}

The authors are grateful to Carole Bresson and Sandra Mounicou for helpful discussions. Tissues were received from the Sydney Brain Bank, which is supported by Neuroscience Research Australia and the University of New South Wales, and from The London Neurodegenerative Diseases Brain Bank, which receives funding from the Medical Research Council and the Brains for Dementia Research program, jointly funded by Alzheimer's Research UK and Alzheimer's Society. We thank the Bioprot Platform of the Neurocampus facilities at the University of Bordeaux funded by the LABEX BRAIN (ANR-10-LABX-43) with the help of N. Sans and M. Sainlos. Parts of this research were carried out at beamline P06/ PETRA III at DESY, a member of the Helmholtz Association (HGF), supported by the project CALIPSOplus under the grant agreement 730872 from the EU Framework Programme HORIZON 2020. The AIFIRA facility is supported by CNRS/ IN2P3, University of Bordeaux and the Région Nouvelle Aquitaine. B.G.T. and K.L.D. are funded by the National Health and Medical Research Council of Australia (1181864), Parkinson's NSW (Australia), the University of Sydney (Biomedical Science), The Motor Neurone Disease Research Institute of Australia, The Michael J Fox Foundation for Parkinson's Research in partnership with the Shake It Up Australia Foundation, and by ForeFront, a large collaborative research group dedicated to the study of neurodegenerative diseases and funded by the National Health and Medical Research Council of Australia Program grant (1132524), Dementia Research Team grant (1095127), and CogSleep Centre of Research Excellence (1152945). S.J.M.V.M. is a postdoctoral fellow of the Flemish Research Foundation FWO (grant number $12 \mathrm{~S} 5718 \mathrm{~N}$ ).

\section{REFERENCES}

(1) Gilston, B. A.; O'Halloran, T. V. Mechanisms Controlling the Cellular Metal Economy. In Metals in Cells; Culotta, V., Scott, R. A., Eds.; John Wiley \& Sons, Ltd., 2013, pp 3-14.

(2) Crichton, R.; Ward, R. Metal-Based Neurodegeneration: From Molecular Mechanisms to Therapeutic Strategies, 2nd ed.; Wiley, 2013.

(3) Acevedo, K.; Masaldan, S.; Opazo, C. M.; Bush, A. I. JBIC, J. Biol. Inorg. Chem. 2019, 24, 1141-1157.

(4) Szökefalvi-Nagy, Z.; Bagyinka, C.; Demeter, I.; Hollós-Nagy, K.; Kovács, I. Fresenius. J. Anal. Chem. 1999, 363, 469-473.
(5) Gao, Y.; Chen, C.; Chai, Z.; Zhao, J.; Liu, J.; Zhang, P.; He, W.; Huang, Y. Analyst 2002, 127, 1700-1704.

(6) Verbi, F. M.; Arruda, S. C. C.; Rodriguez, A. P. M.; Pérez, C. A.; Arruda, M. A. Z. J. Biochem. Biophys. Methods 2005, 62, 97-109.

(7) Ortega, R. Metallomics 2009, 1, 137.

(8) Finney, L.; Chishti, Y.; Khare, T.; Giometti, C.; Levina, A.; Lay, P. A.; Vogt, S. ACS Chem. Biol. 2010, 5, 577-587.

(9) Raimunda, D.; Khare, T.; Giometti, C.; Vogt, S.; Argüello, J. M.; Finney, L. Metallomics 2012, 4, 921-927.

(10) Matsuyama, S.; Matsunaga, A.; Sakamoto, S.; Iida, Y.; Suzuki, Y.; Ishizaka, Y.; Yamauchi, K.; Ishikawa, T.; Shimura, M. Metallomics 2013, 5, 492-500.

(11) Morgan, M. T.; Bagchi, P.; Fahrni, C. J. J. Am. Chem. Soc. 2011, $133,15906-15909$.

(12) Mounicou, S.; Szpunar, J.; Lobinski, R. Chem. Soc. Rev. 2009, 38, 1119-1138.

(13) Hu, L.; Cheng, T.; He, B.; Li, L.; Wang, Y.; Lai, Y.-T.; Jiang, G.; Sun, H. Angew. Chem., Int. Ed. 2013, 52, 4916-4920.

(14) Chevreux, S.; Roudeau, S.; Fraysse, A.; Carmona, A.; Devès, G.; Solari, P. L.; Mounicou, S.; Lobinski, R.; Ortega, R. Biochimie 2009, 91, 1324-1327.

(15) Roberts, B. R.; Lim, N. K. H.; McAllum, E. J.; Donnelly, P. S.; Hare, D. J.; Doble, P. A.; Turner, B. J.; Price, K. A.; Chun Lim, S.; Paterson, B. M.; Hickey, J. L.; Rhoads, T. W.; Williams, J. R.; Kanninen, K. M.; Hung, L. W.; Liddell, J. R.; Grubman, A.; Monty, J.F.; Llanos, R. M.; Kramer, D. R.; Mercer, J. F. B.; Bush, A. I.; Masters, C. L.; Duce, J. A.; Li, Q.-X.; Beckman, J. S.; Barnham, K. J.; White, A. R.; Crouch, P. J. J. Neurosci. 2014, 34, 8021-8031.

(16) Roudeau, S.; Chevreux, S.; Carmona, A.; Ortega, R. Electrophoresis 2015, 36, 2482-2488.

(17) Tainer, J. A.; Getzoff, E. D.; Richardson, J. S.; Richardson, D. C. Nature 1983, 306, 284-287.

(18) McCord, J. M.; Fridovich, I. J. Biol. Chem. 1969, 244, 60496055.

(19) Wright, G. S. A.; Antonyuk, S. V.; Hasnain, S. S. Q. Rev. Biophys. 2019, 52, No. e12.

(20) Trist, B. G.; Hilton, J. B.; Hare, D. J.; Crouch, P. J.; Double, K. L. Angew. Chem., Int. Ed. 2020, 60, 9215-9246.

(21) Rosen, D. R.; Siddique, T.; Patterson, D.; Figlewicz, D. A.; Sapp, P.; Hentati, A.; Donaldson, D.; Goto, J.; O’Regan, J. P.; Deng, H.-X. Nature 1993, 362, 59-62.

(22) Taylor, J. P.; Brown, R. H.; Cleveland, D. W. Nature 2016, 539, 197-206.

(23) Paré, B.; Lehmann, M.; Beaudin, M.; Nordström, U.; Saikali, S.; Julien, J. P.; Gilthorpe, J. D.; Marklund, S. L.; Cashman, N. R.; Andersen, P. M.; Forsberg, K.; Dupré, N.; Gould, P.; Brännström, T.; Gros-Louis, F. Sci. Rep. 2018, 8, 1-13.

(24) Choi, J.; Rees, H. D.; Weintraub, S. T.; Levey, A. I.; Chin, L.-S. S.; Li, L. J. Biol. Chem. 2005, 280, 11648-11655.

(25) Trist, B. G.; Davies, K. M.; Cottam, V.; Genoud, S.; Ortega, R.; Roudeau, S.; Carmona, A.; De Silva, K.; Wasinger, V.; Lewis, S. J. G.; Sachdev, P.; Smith, B.; Troakes, C.; Vance, C.; Shaw, C.; Al-Sarraj, S.; Ball, H. J.; Halliday, G. M.; Hare, D. J.; Double, K. L. Acta Neuropathol. 2017, 134, 113-127.

(26) Hilton, J. B.; White, A. R.; Crouch, P. J. J. Mol. Med. 2015, 93, 481-487.

(27) Tokuda, E.; Nomura, T.; Ohara, S.; Watanabe, S.; Yamanaka, K.; Morisaki, Y.; Misawa, H.; Furukawa, Y. Biochim. Biophys. Acta, Mol. Basis Dis. 2018, 1864, 2119-2130.

(28) Larner, F.; McLean, C. A.; Halliday, A. N.; Roberts, B. R. Inorganics 2019, 7, 86 .

(29) Schroer, C. G.; Boye, P.; Feldkamp, J. M.; Patommel, J.; Samberg, D.; Schropp, A.; Schwab, A.; Stephan, S.; Falkenberg, G.; Wellenreuther, G.; Reimers, N. Nucl. Instrum. Methods Phys. Res., Sect. A 2010, 616, 93-97.

(30) da Cunha, M. M. L.; Trepout, S.; Messaoudi, C.; Wu, T. D.; Ortega, R.; Guerquin-Kern, J. L.; Marco, S. Micron 2016, 84, 23-36.

(31) Jurowski, K.; Buszewski, B.; Piekoszewski, W. Talanta 2015, $131,273-285$. 
(32) Pergande, M.; Cologna, S. Proteomes 2017, 5, 4.

(33) Davies, K. M.; Bohic, S.; Carmona, A.; Ortega, R.; Cottam, V.; Hare, D. J.; Finberg, J. P. M.; Reyes, S.; Halliday, G. M.; Mercer, J. F. B.; Double, K. L. Neurobiol. Aging 2014, 35, 858-866.

(34) Bourassa, M. W.; Brown, H. H.; Borchelt, D. R.; Vogt, S.; Miller, L. M. Front. Aging Neurosci. 2014, 6, 110.

(35) Sirangelo, I.; Iannuzzi, C. Molecules 2017, 22, 1429.

(36) McAllum, E. J.; Roberts, B. R.; Hickey, J. L.; Dang, T. N.; Grubman, A.; Donnelly, P. S.; Liddell, J. R.; White, A. R.; Crouch, P. J. Neurobiol. Dis. 2015, 81, 20-24.

(37) Williams, J. R.; Trias, E.; Beilby, P. R.; Lopez, N. I.; Labut, E. M.; Bradford, C. S.; Roberts, B. R.; McAllum, E. J.; Crouch, P. J.; Rhoads, T. W.; Pereira, C.; Son, M.; Elliott, J. L.; Franco, M. C.; Estévez, A. G.; Barbeito, L.; Beckman, J. S. Neurobiol. Dis. 2016, 89, $1-9$.

(38) Philips, T.; Rothstein, J. D. Curr. Protoc. Pharmacol. 2015, 2015, 5.67.1-5.67.21.

(39) Rodriguez, J. a.; Valentine, J. S.; Eggers, D. K.; Roe, J. a.; Tiwari, A.; Brown, R. H.; Hayward, L. J. J. Biol. Chem. 2002, 277, 1593215937.

(40) Hayward, L. J.; Rodriguez, J. a.; Kim, J. W.; Tiwari, A.; Goto, J. J.; Cabelli, D. E.; Valentine, J. S.; Brown, R. H. J. Biol. Chem. 2002, 277, 15923-15931.

(41) Münch, C.; Bertolotti, A. J. Mol. Biol. 2010, 399, 512-525.

(42) Doucette, P. A.; Whitson, L. J.; Cao, X.; Schirf, V.; Demeler, B.; Valentine, J. S.; Hansen, J. C.; Hart, P. J. J. Biol. Chem. 2004, 279, 54558-54566.

(43) Lelie, H. L.; Liba, A.; Bourassa, M. W.; Chattopadhyay, M.; Chan, P. K.; Gralla, E. B.; Miller, L. M.; Borchelt, D. R.; Valentine, J. S.; Whitelegge, J. P. J. Biol. Chem. 2011, 286, 2795-2806.

(44) Rhoads, T. W.; Lopez, N. I.; Zollinger, D. R.; Morré, J. T.; Arbogast, B. L.; Maier, C. S.; DeNoyer, L.; Beckman, J. S. Anal. Biochem. 2011, 415, 52-58.

(45) Rhoads, T. W.; Williams, J. R.; Lopez, N. I.; Morré, J. T.; Bradford, C. S.; Beckman, J. S. J. Am. Soc. Mass Spectrom. 2013, 24, 115-124. 